\title{
Tissue- and substrate-dependent responses of oxidative phosphorylation to dietary protein level in chicks
}

\author{
BY MASAHIRO TANAKA, TERU ISHIBASHI, KATSUYUKI OKAMOTO \\ AND MASAAKI TOYOMIZU*† \\ Animal Nutrition, Department of Agriculture and Graduate School of Science and Technology, \\ Niigata University, 2-8050 Ikarashi, Niigata, 950-21, Japan
}

(Received 7 July 1992 - Accepted 9 October 1992)

\begin{abstract}
The ADP: $O$ values in both cardiac and hepatic mitochondria have significantly decreased with an increase in protein level after 7,14 and $21 \mathrm{~d}$ of feeding (Toyomizu et al. 1992). The present studies were undertaken to clarify tissue-specific effects of dietary protein levels on oxidative phosphorylation in the liver, kidney, skeletal muscles and small intestine and to characterize oxidative metabolism with diverse substrates in the liver. Chicks were fed on semi-purified diets of different protein levels $(7,25,43$ and $61 \%$ of metabolizable energy content) for $21 \mathrm{~d}$. The responses of protein levels to oxidative phosphorylation showed tissue-dependency; although liver mitochondria of chickens fed on higherprotein diets exhibited reduced ADP: $O$ values and state 3, neither changes in ADP: $O$ value nor state 3 and state 4 rates were observed in the isolated mitochondria from kidney and skeletal muscles. Small intestinal mucosal mitochondria from chickens fed on a high $(61 \%)$-protein-energy diet showed significantly reduced $A D P: O$ value and respiratory control ratio when compared with medium-proteinenergy diets ( 25 and $43 \%$ ). In liver mitochondria showing the most sensitive dependency to the levels of dietary protein, the ADP: $O$ value decreased with increasing protein levels when pyruvate + malate- or glutamate-requiring complexes I, III and IV of the electron transport chain were used as substrates, but it did not change when succinate-requiring complexes II, III and IV or ascorbate + tetramethyl-pphenylenediamine requiring complex IV was used. These results imply that impaired oxidative phosphorylation capacities with increasing dietary protein levels may be associated with functional damage to the respiratory chain for electron flow from NAD-linked substrates to the ubiquinone pool.
\end{abstract}

Dietary protein: Oxidative phosphorylation: Tissue specificity: Chicken

We have previously shown that the level of dietary protein is an important determinant of oxidative phosphorylation with pyruvate + malate as substrates in rat heart mitochondria (Toyomizu \& Clandinin, 1993). When the dietary protein and fat levels were altered, feeding 70\% protein-energy diets reduced the ADP:O value compared with the $30 \%$ protein-energy level, but no difference was observed between low-fat and high-fat groups. Further, the impairment of oxidative phosphorylation in rats fed on a high-protein diet was supported by our finding with liver and heart mitochondria in chickens (Toyomizu et al. 1992). A parallel correlation between ADP: O values for liver mitochondria and body fat was also observed in the chickens fed on diets with different levels of protein, implying that the reduction in oxidative phosphorylation may partly contribute to the decrease in body fat in chickens.

However, compensatory mechanisms, including increased oxidative phosphorylation in the other tissues, could be proposed for the higher-protein-fed groups, considering that

$\uparrow$ For reprints. Present address: Animal Nutrition, Faculty of Agriculture, Tohoku University, I-I, Tsutsumidori-Amamiyamachi, Sendai, 981 Japan. 


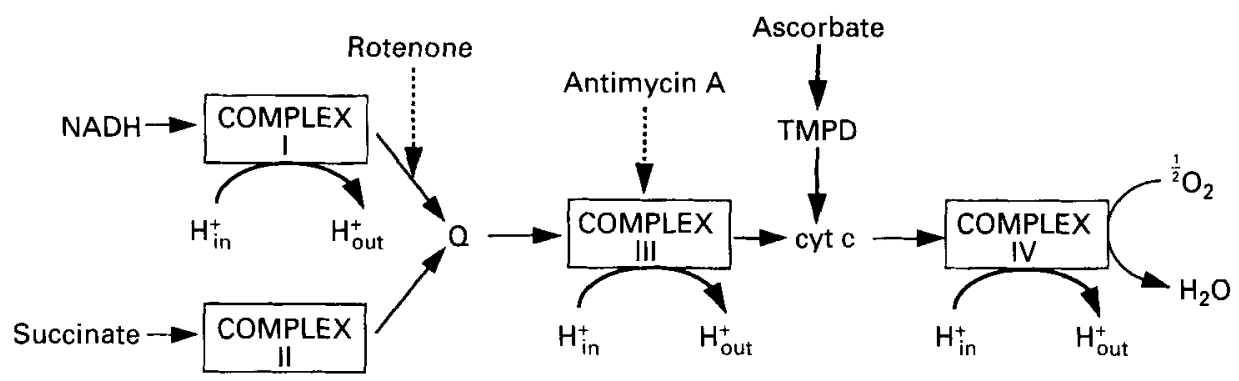

Fig. 1. The electron transport chain. Q, ubiquinone; cyt c, cytochrome c. The electron transport complexes (located in the inner mitochondrial membrane) are complex I (NADH : ubiquinone oxidoreductase; EC 1.6.5.3), complex II (succinate: ubiquinone oxidoreductase; EC 1.3.99.1), complex IIl (ubiquinol:ferricytochrome-c oxidoreductase; $E C 1.10 .2 .2$ ), and complex IV (ferrocytochrome-c:oxygen oxidoreductase; $E C 1.9 .3 .1-2$ ).

$\rightarrow$, The electron flow through the electron transport chain; .... specific inhibitors for each complex (rotenone for complex $I$ and antimycin A for complex III). Different substrates were used to study the characteristics of $\mathrm{O}_{2}$ consumption: pyruvate, malate, and L-glutamate, which generate intramitochondrial NADH; succinate, which provides electrons and the ubiquinone level; and ascorbate + tetramethyl-pphenylenediamine (TMPD), which reduces the respiratory chain at the cyt c level.

various ages, dietary conditions, etc. may have variable effects on different tissues. In particular, a form of tissue-specific protein metabolism has been reported. It has been emphasized that there are no significant differences in fractional protein synthesis in rat liver between weaning and senility, while the rates progressively decline in the kidney, intestine and whole body throughout life (Goldspink \& Kelly, 1984; Goldspink et al. 1984). Reeds (1989) pointed out the significance of tissue-dependency of protein turnover in as much as changes in whole-body protein synthesis when feeding a dietary supplement of carbohydrate were not necessarily reflected in those in protein synthesis of the hindquarter tissue. In terms of mitochondrial oxidative activity it has already been observed that the liver does not respond as well as the heart or muscle to different fat composition in diet (Houtsmuller et al. 1970; Christophersen \& Bremer, 1972) and to synthetic glucocorticoid (Martens et al. 1991). In rats the thermogenic responses with uncoupling to cold adaptation and hyperphagia induced by feeding a balanced, palatable cafeteria diet (diet-induced thermogenesis) were shown specifically in brown adipose tissue (Rothwell et al. 1983; Rothwell \& Stock, 1987; Trayhurn et al. 1987) but not other tissues, namely liver and muscle. On the other hand, in birds an effector of diet-induced thermogenesis analogous to the brown adipose tissue of some mammals has yet to be identified (Johnston, 1971). In this way there was no direct evidence for the existence of thermogenic responses with uncoupling effects of oxidative phosphorylation except in liver and heart in the chicken.

Other compensatory changes may occur in the other site-entrance for substrates except pyruvate + malate: if one site is somewhat less active the other entry points would be used to a greater extent. Recent studies showed that oxidation of the NAD-linked substrate was less sensitive to glucocorticoid than that of the FAD-linked one (Martens et al. 1991), and that the inhibition of the uncoupled state by arachidonic acid was more marked in NADlinked than in FAD-linked respiration (Takeuchi et al. 1991).

The present study was conducted, therefore, to clarify tissue-specific effects of dietary protein levels on the oxidative phosphorylation in the liver, kidney, skeletal muscles and small intestine. Further study was carried out to elucidate the utilization of various substrates requiring complexes I, III and IV, complexes II, III and IV and complex IV in the respiratory chain (Fig. 1) in liver mitochondria of chickens fed on diets with different protein levels. 
Table 1. Composition of experimental diets* $(\mathrm{g} / \mathrm{kg})$

\begin{tabular}{lrrrr}
\hline \hline & & & & \\
Protein levels as \\
metabolizable energy \\
(\% total energy) $\ldots$
\end{tabular}

* All the diets contained the same amount of cellulose, fat, minerals, and vitamins per unit metabolizable energy

$\dagger$ Protein consisted of an isolated soya-bean protein-soya-bean meal-L-methionine-L-lysine monohydrochloride $(657: 326: 12: 5$, by wt) mixture.

$\ddagger$ Carbohydrate consisted of yellow maize- $\alpha$-maize starch-glucose $(2: 3: 5$, by wt) mixture.

$\S$ See Akiba \& Matsumoto (1978).

\section{MATERIALS AND METHODS}

\section{Animals and diets}

Male chicks (Arbor Acres or Cobb) were obtained from a commercial hatchery (Ishida Poultry and Egg's Co. Ltd, Nagaoka 940, Japan) at $1 \mathrm{~d}$ of age. They were housed in electrically-heated batteries and provided with water and a commercial starter diet ad lib. for the first $13 \mathrm{~d}$. The chicks were randomly divided into four groups. They were housed individually in wire cages under controlled light ( $14 \mathrm{~h}$ light and $10 \mathrm{~h}$ dark) and temperature $\left(25 \pm 2^{\circ}\right)$. In each of several series of experiments, four experimental diets providing protein at 7, 25 (control diet), 43, and $61 \%$ of total energy (PME) were formulated on a metabolizable energy (ME) basis by substituting the carbohydrate (CME) at a constant fat level (FME; Table 1). The carbohydrate source was a yellow maize- $\alpha$-maize starch-glucose $(2: 3: 5$, by wt) mixture. The fat source was soya-bean oil. The protein source was an isolated soya-bean protein-soya-bean meal-L-methionine-L-lysine monohydrochloride $(657: 326: 12: 5$, by wt) mixture. All the diets contained the same amount of cellulose, fat, minerals and vitamins on a per MJ metabolizable energy basis. Four or five chicks from each group at $21 \mathrm{~d}$ of the feeding regimen were killed by cervical dislocation.

\section{Isolation of mitochondria}

Liver and kidney mitochondria were prepared according to the methods of Hoppel et al. (1979). Briefly, the liver and kidney were rinsed, blotted, weighed, minced, and washed with cold MSM buffer containing $220 \mathrm{~mm}$-mannitol, $70 \mathrm{~mm}$-sucrose, $5 \mathrm{~mm}$-3-(N-mor- 
pholino)propanesulphonic acid (Mops), pH 7.4. A suspension ( $100 \mathrm{~g} / \mathrm{l})$ of the minced liver in cold MSM buffer containing 2 mM-EDTA was homogenized in a Potter-Elvehjem homogenizer with a loose-fitting pestle. Nuclei and cell debris were removed by centrifugation at $400 \mathrm{~g}$ for $10 \mathrm{~min}$, and mitochondria were isolated by centrifugation of the resulting supernatant fraction at $7000 \mathrm{~g}$ for $10 \mathrm{~min}$. The resulting mitochondrial pellet was washed twice with MSM buffer and finally the pellet was suspended with MSM buffer.

Skeletal muscle mitochondria were isolated from pectoralis profundus or biceps femoris by the procedure of Lee et al. (1979). The minced tissue was suspended in the Chappell-Perry medium (Chappell \& Perry, 1954) containing $100 \mathrm{~mm}-\mathrm{KCl}, 50 \mathrm{~mm}-\mathrm{Tris}$ hydrochloride, $1 \mathrm{~mm}-\mathrm{ATP}, 5 \mathrm{~mm}-\mathrm{MgCl}_{2}, 1 \mathrm{~mm}$-EDTA, pH 7.5. This suspension was treated with Nagarse, and homogenized with an Ultra-Turrax (Janke \& Kunkel GmbH, Germany). The homogenate was centrifuged at $600 \mathrm{~g}$ for $10 \mathrm{~min}$, and the supernatant fraction was centrifuged at $14000 \mathrm{~g}$ for $10 \mathrm{~min}$. The pellet was suspended in a medium containing $100 \mathrm{~mm}-\mathrm{KCl}, 50 \mathrm{~mm}$-Tris hydrochloride, $0.2 \mathrm{mM}-\mathrm{ATP}, 1 \mathrm{~mm}-\mathrm{MgCl}_{2}, 0.2 \mathrm{~mm}-$ EDTA, $10 \mathrm{~g}$ albumin/1, pH 7.5. The suspension was centrifuged at $7000 \mathrm{~g}$ for $10 \mathrm{~min}$, then the resulting pellet was resuspended in the modified Chappell-Perry medium described previously but without albumin. This was centrifuged at $3500 \mathrm{~g}$ for $10 \mathrm{~min}$, and finally the pellet was resuspended with $0 \cdot 25 \mathrm{M}$-sucrose.

Small intestinal mucosal mitochondria were prepared by the method of Lawrence \& Davies (1986). The mucosal scrapings from the intestine was stirred with the DEAEcellulose suspension. This suspension consisted of $10 \mathrm{~g} \mathrm{DEAE}$ cellulose in isolation medium A containing $70 \mathrm{~mm}$-sucrose, $220 \mathrm{~mm}$-mannitol, $2 \mathrm{mM}-\mathrm{N}$-2-hydroxyethylpiperazine- $\mathrm{N}^{\prime}-2-$ ethanesulphonic acid (Hepes), 0.5 mm-ethylene glycol bis( $\beta$-aminoethyl-ether)-N,N, $N^{\prime}, N^{\prime}-$ tetraacetic acid (EGTA), 0.1 mM-phenylmethylsulphonyl fluoride (PMSF), $3 \cdot 7 \mathrm{~g}$ albumin/l, $\mathrm{pH} 7 \cdot 4$. The mucosal suspension was homogenized using a Potter-Elvehjem homogenizer. This homogenate was centrifuged at $750 \mathrm{~g}$ for $10 \mathrm{~min}$. The resulting supernatant fraction was recentrifuged at $10000 \mathrm{~g}$ for $7 \mathrm{~min}$. The crude mitochondrial pellet was suspended in isolation medium $\mathrm{A}$. This suspension was centrifuged at $14000 \mathrm{~g}$ for $7 \mathrm{~min}$. The resulting pellet was resuspended in isolation medium B containing $70 \mathrm{~mm}$-sucrose, $220 \mathrm{~mm}$-mannitol, $2 \mathrm{~mm}-\mathrm{Hepes}, 12 \mathrm{~g}$ albumin $/ 1$ ( $\mathrm{pH} 7 \cdot 4)$. The suspension was centrifuged at $14000 \mathrm{~g}$ for $7 \mathrm{~min}$ and finally the pellet was suspended with isolation medium $B$.

All procedures were performed at $0-4^{\circ}$.

\section{Measurement of oxygen consumption rate}

$\mathrm{O}_{2}$ consumption was measured polarographically with a Clark electrode no. 5331 (Yellow Springs Instrument Co. Inc., Ohio, USA) by using a YSI model $5300 \mathrm{O}_{2}$ monitor linked to a recorder (U-228; Nippon Denshi Kagaku Co. Ltd, Kyoto, Japan). The incubation medium for liver or kidney mitochondria containing $80 \mathrm{~mm}-\mathrm{KCl}, 50 \mathrm{~mm}-\mathrm{Mops}$, $5 \mathrm{~mm}-\mathrm{KH}_{2} \mathrm{PO}_{4}, 1 \mathrm{~mm}-\mathrm{EGTA}, 1 \mathrm{~g}$ albumin/1, pH 7.0 (Hoppel et al. 1979). The medium for skeletal muscle mitochondria consisted of $150 \mathrm{~mm}$-sucrose, $25 \mathrm{~mm}$-Tris hydrochloride, and $10 \mathrm{~mm}-\mathrm{KH}_{2} \mathrm{PO}_{4} \mathrm{pH} 7.5$ (Lee et al. 1979). The medium for small intestinal mucosal mitochondria contained $70 \mathrm{~mm}$-sucrose, $220 \mathrm{~mm}$-mannitol, $2 \mathrm{~mm}$-Hepes, $0.75 \mathrm{~mm}$-EDTA, $0.50 \mathrm{~mm}-\mathrm{EGTA}, 2.5 \mathrm{~mm}-\mathrm{MgCl}_{2}, 2.5 \mathrm{~mm}-\mathrm{KH}_{2} \mathrm{PO}_{4}, 1.3 \mathrm{~g}$ albumin/1, $\mathrm{pH} 7.4$ (Lawrence \& Davies, 1986).

Substrate concentrations were $10 \mathrm{~mm}$-pyruvate $+2.5 \mathrm{~mm}$-malate, $10 \mathrm{mM}$-L-glutamate, $10 \mathrm{~mm}$-succinate, or $0.5 \mathrm{~mm}$-tetramethyl-p-phenylenediamine (TMPD) + 5.0 mm-ascorbate; other additions were $10 \mathrm{~mm}$-malonate, $3.75 \mu \mathrm{M}$-rotenone or $0.4 \mu \mathrm{M}$-antimycin $\mathrm{A}$. The system was equilibrated with mitochondria at $37^{\circ}$; then the rate of $\mathrm{O}_{2}$ consumption was determined. The state 3 respiratory rate was initiated by $220 \mathrm{nmol} \mathrm{ADP}$, the state 4 respiratory rate after exhaustion of $\mathrm{ADP}$, respiratory control ratios and $\mathrm{ADP}: \mathrm{O}$ values 
were determined on third and subsequent cycles as described by Chance \& Williams (1956) and Chappell (1964). The exact concentration of added ADP was determined spectrophotometrically (Jaworek et al. 1974). All determinations were made without undue lapse of time after isolation of mitochondria. The solubility of $\mathrm{O}_{2}$ at $37^{\circ}$ was assumed to be $0 \cdot 39 \mu \mathrm{g}$ atoms $\mathrm{O}_{2} / \mathrm{ml}$ (Clandinin, 1978). To avoid bias we measured $\mathrm{O}_{2}$ consumption of each mitochondrial preparation from the four dietary groups according to a systematically randomized order that was different on each day. Oxidation rate was expressed in ng $\mathrm{O}_{2} / \mathrm{mg}$ mitochondrial protein per min. Protein was measured by a colorimetric method (Lowry et al. 1951), except for small intestinal mucosal protein determination which was carried out by the Bio-Rad dye-binding procedure (Bio-Rad GmbH, Munich, Germany).

\section{Statistical procedure}

With one-way analysis the effect of treatment on mitochondrial functions was examined to separate the effect of dietary protein levels. The significance level for individual group comparisons was $P<0.05$ using Duncan's least significant difference multiple-range test (SAS Institute Inc., 1985).

\section{RESULTS}

Body-weight gain and food consumption

Representative body weights and feed consumption of chickens are shown in Fig. 2. The body-weight gain increased to a maximum level with $43 \%$ protein-energy diet and decreased thereafter. No significant differences in body-weight gain was observed in chicks fed on $43 \%$ protein-energy diet when compared with $25 \%$ protein energy diet. Similar results were obtained with all the experiments. Food intake expressed as metabolizable energy for chicks fed on a $7 \%$ protein-energy diet especially was lower than that for chicks fed on $43 \%$ protein-energy diet when compared with $25 \%$ protein-energy diet. Similar their food intake to satisfy their energy requirements (Hill \& Dansky, 1954; Powell et al. 1972). Here, the chicks fed on a $7 \%$ protein-energy diet could not adjust their intake to compensate for differences in dietary content. It is quite possible that body size might not become large enough so that stomach distension would be a limiting factor in food intake (Forbes, 1986).

\section{Oxidative phosphorylation in the liver, kidney, skeletal muscles, and small intestinal mucosa}

Table 2 shows the effects of dietary protein level on oxidative phosphorylation in the liver, kidney, skeletal muscles, pectoralis profundus and biceps femoris, and small intestinal mucosa. The rates of $\mathrm{O}_{2}$ uptake and ADP: $\mathrm{O}$ values observed were similar in magnitude to those previously reported for rat liver, kidney, skeletal muscles, and small intestinal mucosa (Lee et al. 1979; Lawrence \& Davies, 1986; Toyomizu et al. 1992). Although the rates of state 3 and ATP synthesized in liver with pyruvate + malate plus malonate significantly decreased with increasing protein levels in diet, changes were not observed in the kidney, skeletal muscles, and small intestinal mucosa. The rate of state 4 oxidation was not affected by dietary protein in the liver, kidney or skeletal muscles, but it was affected in intestinal mucosa, where the rate for chickens fed on a $61 \%$ protein-energy diet significantly increased compared with groups fed on the lower-protein diets. Respiratory control ratios in all tissues were significantly unchanged by dietary protein level except when glutamate + malate were used as substrates in small intestinal mucosa. Determination of ADP:O values in mitochondria also indicate differences in the response to protein level among tissues; that is, no changes in ADP:O values were observed in the isolated mitochondria from the kidney or skeletal muscles, whereas liver mitochondria exhibited a 

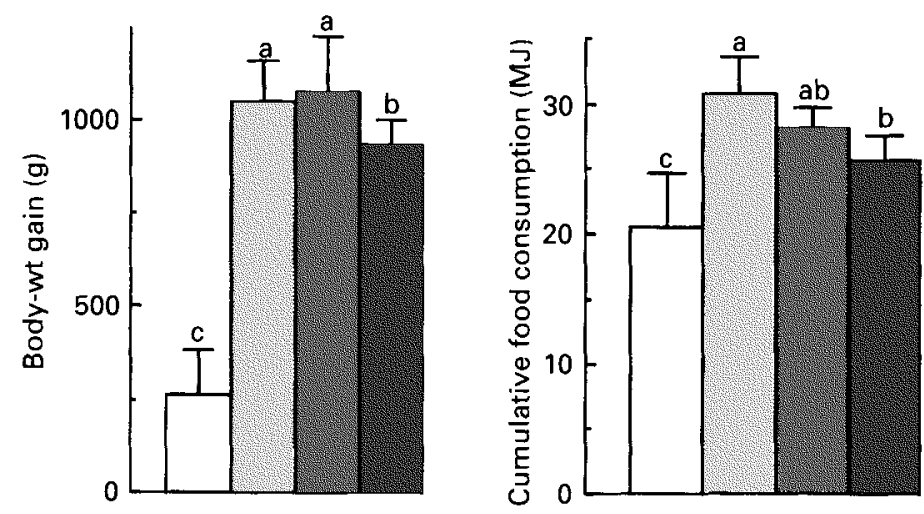

Fig. 2. Effect of dietary protein level on body-weight gain and cumulative food consumption over $21 \mathrm{~d}$ of feeding period: $\square, 7 \% ;$, $\square$, $5 \%$; 圆, 43\%; $61 \%$ total energy of diet provided as protein. Differences in means were tested by Duncan's multiple comparison test. Values are means and standard deviations represented by vertical bars. Means with different superscript letters were significantly different $(P<0.05)$.

reduced $A D P: O$ value with increasing protein level, and intestinal mucosal mitochondria of chickens fed on a $61 \%$ protein-energy diet showed a significantly reduced ADP:O value compared with 25 and $43 \%$ protein-energy diets.

\section{Oxidative phosphorylation with diverse substrate}

As illustrated in Fig. 1, the electron transport chain transports electrons from NADH or FADH to $\mathrm{O}_{2}$ and produces a transmembranous proton gradient used for the generation of ATP (Hatefi, 1985). Determination of oxidative phosphorylation was investigated in intact liver mitochondria isolated from chickens fed on diets of different protein levels for $21 \mathrm{~d}$ (Table 3). There were no differences in state 3 and state 4 oxidation rates, in the amount of ATP synthesized, nor in the respiratory control index for pyruvate + malate, glutamate, succinate, and ascorbate + TMPD as substrates among groups fed at various dietary protein levels. However, ADP: $O$ values were significantly reduced with increasing dietary protein level for pyruvate + malate and glutamate as substrates requiring complexes I, III and IV of the electron transport chain, but they showed no changes for either succinate-requiring complexes II, III and IV or for ascorbate + TMPD-requiring complex IV. Similar results for ADP : O values for pyruvate + malate or succinate as substrates were obtained with liver mitochondria prepared using an isolation medium differing from the medium used in the present experiment from animals under the same condition of diets and environment (values not shown). The reduction in ADP:O values for a group fed on a $61 \%$ protein-energy diet was approximately $20 \%$ for pyruvate + malate and $10 \%$ for glutamate when compared with a group fed on a $7 \%$ protein-energy diet.

\section{DISCUSSION}

We have already shown that the ADP: $O$ values in both cardiac and hepatic mitochondria are significantly decreased with increasing protein levels after 7, 14, and $21 \mathrm{~d}$ of feeding (Toyomizu et al. 1992). However, it can not be seen whether changes of this magnitude in both hepatic and cardiac mitochondrial oxidative phosphorylation activity would be sufficient enough to reconcile decreases in both weight of and percentage of carcass fat with increasing dietary protein level. In fact, Webster (1981) pointed out the significance of analysis on an organ-by-organ basis of differences in heat production between nutritional 


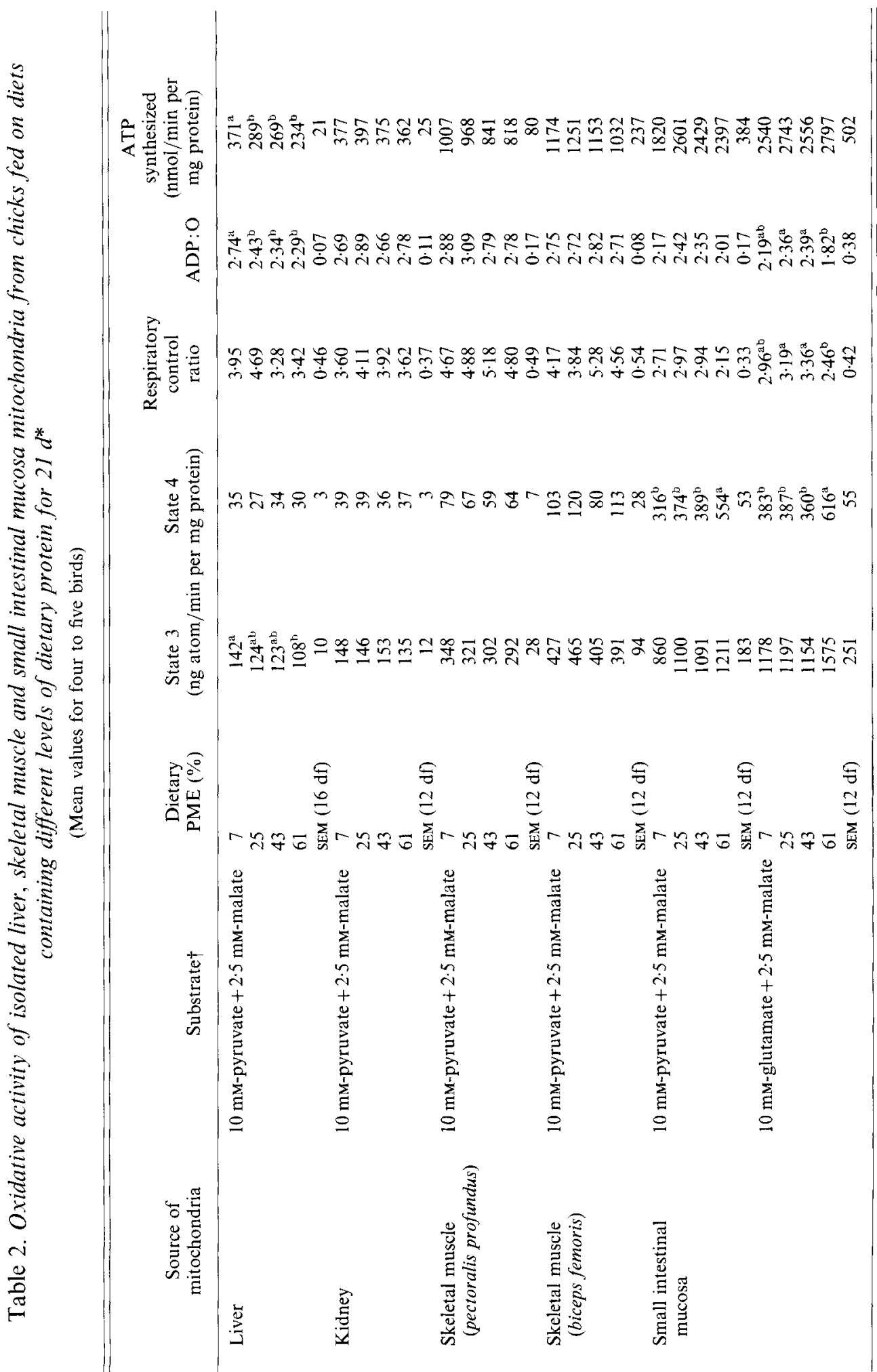

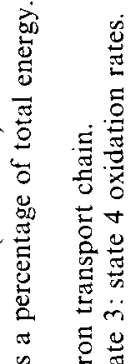

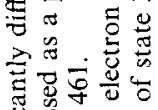

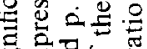
总象它

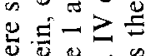

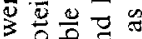

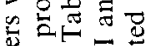

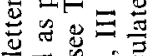

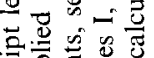

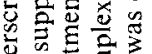

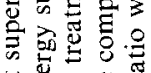
亲它 氙

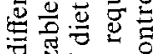
Nㅜㅇ

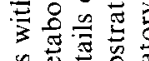
क

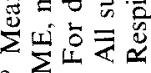

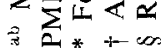




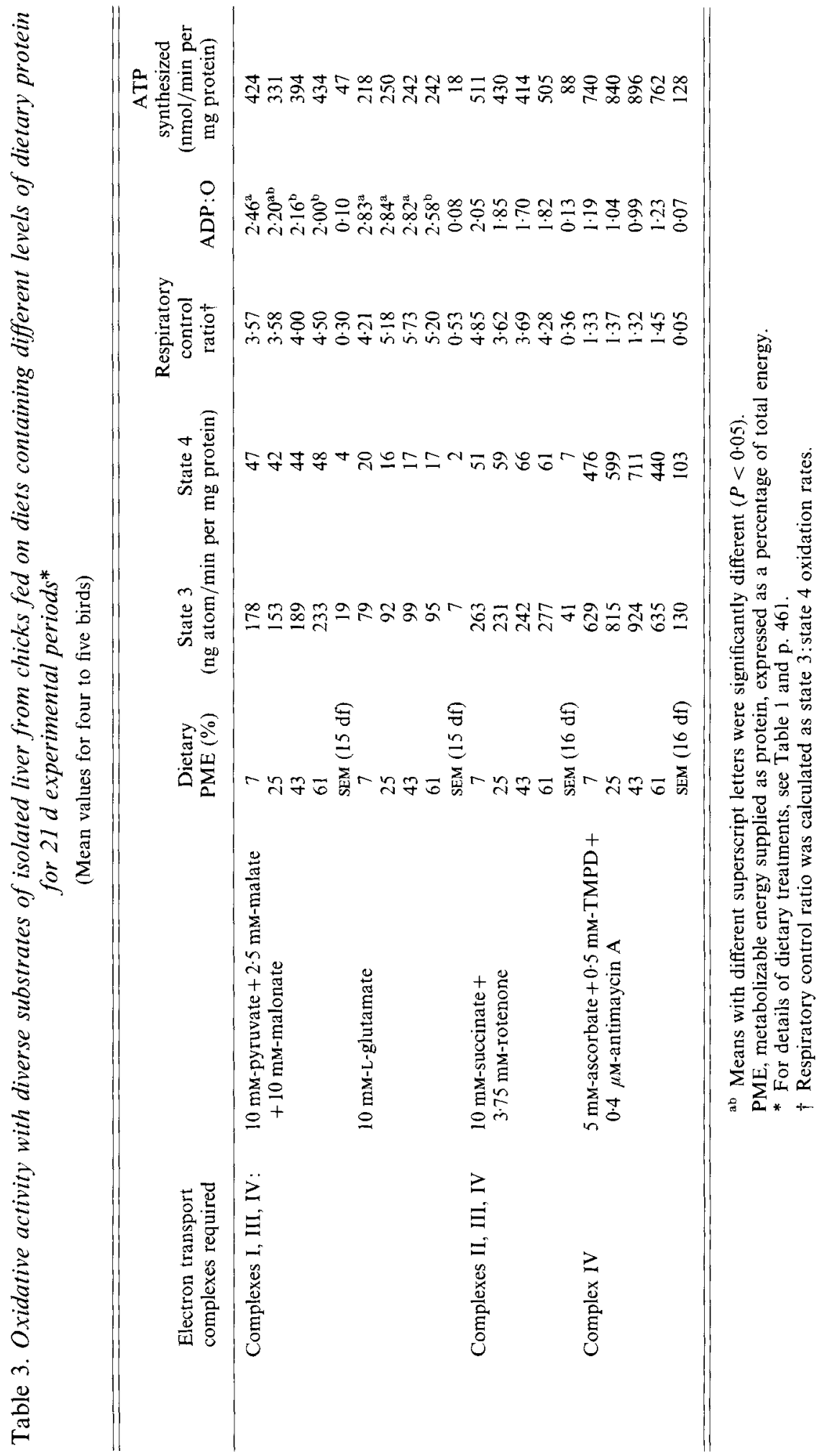


conditions. Differences in response of thermogenesis to low-protein diets have been found between brown adipose tissue and liver (Rothwell et al. 1983). We conducted the present study, therefore, to determine whether dietary protein levels affect mitochondrial oxidative phosphorylation in the kidney, skeletal muscles and small intestinal mucosa as well as in the liver.

Mitochondria isolated from the small intestine, skeletal muscle and kidney exhibited, respectively, 8.9, 2.6, and 1.2 times higher $\mathrm{O}_{2}$ uptake in state 3 oxidation than those from the liver. In the present study the effects of dietary protein on oxidative phosphorylation were shown to be tissue-specific, with differences between liver, kidney, skeletal muscle and small intestinal mucosa. Consistent with our previous studies (Toyomizu et al. 1992), in liver mitochondria ADP: $O$ value and ATP synthesis significantly decreased with increasing dietary protein level. A similar reduction in $\mathrm{ADP}: \mathrm{O}$ was observed with mitochondria isolated from small intestinal mucosa in chicks fed on a high-protein diet. It is conceivable that reduced oxidative phosphorylation in livers and small intestines in chickens fed on a high-protein diet might be caused by metabolites from dietary protein such as amino acids and their derivatives. This is partly supported by findings with chickens fed ad lib. by Tinker et al. (1986), who reported that the liver removed a number of amino acids mainly supplied by the diet and the major metabolite fluxes were across the liver. Therefore, oxidative phosphorylation capacity in the kidney or skeletal muscle would be less affected by the protein level in the diet than that of the liver and intestinal mucosa. Alternatively, the responsiveness of oxidative phosphorylation in different tissues to a certain chemical compound, which is generated as a result of eating a high-protein diet, could vary. In support of this hypothesis, the effect of hormones on mitochondrial energy metabolism was shown to vary with different organs (Martens et al. 1991).

On the other hand, feeding a low-protein diet also reduced ADP:O value in the mucosal mitochondria (Table 2). It has been reported that fat malabsorption is often present in protein -energy malnutrition (Holemans \& Lambrechts, 1955; Gomez et al. 1956). Truswell (1975) pointed out that the most important reason for fat malabsorption was mucosal atrophy. This lower oxidative phosphorylation capacity by treatments with low-protein diets might induce such a mucosal atrophy.

The present study also established that changes in oxidative phosphorylation capacity relating to dietary protein level were dependent on a variety of mitochondrial substrates. As illustrated in Fig. 1, the electron transport chain is located in the inner mitochondrial membrane. The step-by-step transfer of electrons from $\mathrm{NADH}$ or FADH to $\mathrm{O}_{2}$ produces a transmembranous proton gradient used for the generation of ATP (Hatefi, 1985). The decreased $A D P: O$ values with increasing protein level were observed in liver mitochondria isolated from chicks when malate + pyruvate plus malonate were used as the NAD-linked substrates. In the case of another NAD-linked substrate, glutamate, ADP : O values were also similarly reduced with increasing dietary protein. On the other hand, in the case of an alternative site of entry for substrates, such as succinate plus rotenone or ascorbate + TMPD plus antimycin $\mathrm{A}$, the oxidative phosphorylation capacities were not affected by dietary protein level (Table 3). These results suggested that impaired oxidative phosphorylation with NAD-linked substrates in chicks fed on high-protein diets may be induced by a defect in the process of the electron flow from NAD-linked substrates and NADH dehydrogenase (EC 1.6.5.3) to the ubiquinone pool, and complex I, given that malate + pyruvate or glutamate require complexes I, II and IV of the electron transport chain but that succinate requires complexes II, III and IV, and ascorbate + TMPD require complex IV.

The inner membranes of intact mitochondria are normally impermeable to NADH, which is oxidized on the matrix face of the membrane by a FMN-containing component, NADH dehydrogenase (Nicholls, 1981). In the present experiment exogenous NADH, 
regardless of dietary treatment, did not enhance basal mitochondrial respiration in the liver (result not shown), indicating that the decreased ADP: $O$ value with increasing dietary protein level might not be caused by the structural damage to the inner membrane.

In conclusion, the response of mitochondrial energy metabolism to dietary protein level is tissue-specific, with the difference being between the sensitive tissues (liver, small intestinal mucosa) and the insensitive tissues (kidney, skeletal muscle). In addition, it is possible that the decreased oxidative phosphorylation capacities with increasing dietary protein level may be associated with functional damage of the respiratory chain for only the electron flow from NAD-linked substrates and NADH dehydrogenase to the ubiquinone pool.

Financial support was provided by a grant-in-aid (no. 02856072) for Scientific Research from the Ministry of Education, Science and Culture, Japan.

\section{REFERENCES}

Akiba, Y. \& Matsumoto, T. (1978). Effects of force-feeding and dietary cellulose on liver lipid accumulation and lipid composition of liver and plasma in growing chicks. Journal of Nutrition 108, 739-748.

Chance, B. \& Williams, G. R. (1956). The respiratory chain and oxidative phosphorylation. Advances in Enzymology 17, 65-134.

Chappell, J. B. (1964). The oxidation of citrate, isocitrate and cis-aconitate by isolated mitochondria. Biochemical Journal 90, 225-237.

Chappell, J. B. \& Perry, S. V. (1954). Biochemical and osmotic properties of skeletal muscle mitochondria. Nature 173, $1094-1095$.

Christophersen, B. O. \& Bremer, J. (1972). Erucic acid - an inhibitor of fatty acid oxidation in the heart. Biochimica et Biophysica Acta $\mathbf{2 8 0}, 506-514$

Clandinin, M. T. (1978). The role of dietary long chain fatty acids in mitochondrial structure and function. Effects on rat cardiac mitochondrial respiration. Journal of Nutrition 108, 273-281.

Forbes, J. M. (1986). The Voluntary Food Intake of Farm Animals, pp. 86-113. London: Butterworth \& Co. Ltd.

Goldspink, D. F. \& Kelly, F. J. (1984). Protein turnover and growth in the whole body, liver and kidney of the rat from the foetus to senility. Biochemical Journal 217, 507-516.

Goldspink, D. F., Lewis, S. E. M. \& Kelly, F. J. (1984). Protein synthesis during the developmental growth of the small and large intestine of the rat. Biochemical Journal 217, 527-534.

Gomez, F., Ramos-Galvan, R., Cravioto, J., Frenk, S., Vazquez Santaella, J. \& de la Pena, C. (1956). Fat absorption in chronic severe malnutrition in children. Lancet ii, 121-122.

Hatefi, Y. (1985). The mitochondrial electron transport and oxidative phosphorylation system. Anmual Review of Biochemistry 54, 1015-1069.

Holemans, K. \& Lambrechts, A. (1955). Nitrogen metabolism and fat absorption in malnutrition and in kwashiorkor. Journal of Nutrition 56, 477-494.

Hill, F. W. \& Dansky, L. M. (1954). Studies of the energy requirements of chickens. 1. The effect of dietary energy level on growth and feed consumption. Poultry Science 33, 112-119.

Hoppel, C., DiMarco, J. P. \& Tandler, B. (1979). Riboflavin and rat hepatic cell structure and function: mitochondrial oxidative metabolism in deficiency states. Journal of Biological Chemistry 254, 4164-4170.

Houtsmuller, U. M. T., Struijk, C. B. \& Van der Beek, A. (1970). Decrease in rate of ATP synthesis of isolated rat heart mitochondria induced by dietary erucic acid. Biochimica et Biophysica Acta 218, 564-566.

Jaworek, D., Gruber, W. \& Bergmeyer, H. U. (1974). Adenosine-5'-diphosphate and adenosine-5'monophosphate. In Methods of Enzymatic Analysis, pp. 2127-2131. [H. U. Bergmeyer, editor]. New York: Academic Press.

Johnston, D. W. (1971). The absence of brown adipose tissue in birds. Comparative Biochemistry and Physiology 40A, $1107-1108$.

Lawrence, C. B. \& Davies, N. T. (1986). A novel, simple and rapid method for the isolation of mitochondria which exhibit respiratory control, from rat small intestinal mucosa. Biochimica et Biophysica Acta 848, 35-40.

Lee, C. P., Martens, M. E., Jankulovska, L. \& Neymark, M. A. (1979). Defective oxidative metabolism of myodystrophic skeletal muscle mitochondria. Muscle and Nerve 2, 340-348.

Lowry, O. H., Rosebrough, N. J., Farr, A. L. \& Randall, R. J. (1951). Protein measurement with the folin phenol reagent. Journal of Biological Chemistry 193, 265-275.

Martens, M. E., Peterson, P. L. \& Lee, C. P. (1991). In vitro effects of glucocorticoid on mitochondrial energy metabolism. Biochimica et Biophysica Acta 1058, 152-160.

Nicholls, D. G. (1982). Bioenergetics, An Introduction to the Chemiosmotic Theory, pp. 99-132. London: Academic Press. 
Powell, T. S., Douglas, C. R., Stonerock, R. H. \& Harms, R. H. (1972). Feed intake of hens fed various levels of energy from feed and/or sucrose-water. Poultry Science 51, 1851.

Reeds, P. J. (1989). Regulation of protein turnover. In Animal Growth Regulation, pp. 183-189 [D. R. Campion, G J. Hausman and R. J. Martin, editors]. New York and London: Plenum Press.

Rothwell, N. J.\& Stock, M. J. (1987). Effect of environmental temperature on energy balance and thermogenesis in rats fed normal or low protein diets. Journal of Nutrition 117, 833-837.

Rothwell, N. J., Stock, M. J. \& Tyzbir, R. S. (1983). Mechanisms of thermogenesis induced by low protein diets. Metabolism 32, 257-261.

SAS Institute Inc. (1985). SAS User's Guide: Statistics, version 5, pp. 433-506. Cary, NC: SAS Institute Inc.

Takeuchi, Y., Morii, H., Tamura, M., Hayaishi, O. \& Watanabe, Y. (1991). A possible mechanism of mitochondrial dysfunction during cerebral ischemia: inhibition of mitochondrial respiration activity by arachidonic acid. Archives of Biochemistry and Biophysics 289, 33-38.

Tinker, D. A., Brosnan, J. T. \& Herzberg, G. R. (1986). Interorgan metabolism of amino acids, glucose, lactate, glycerol and uric acid in the domestic fowl (Gallus domesticus). Biochemical Journal 240, 829-836.

Toyomizu, M. \& Clandinin, M. T. (1993). Effects of dietary protein and fat level on oxidative phosphorylation in rat heart mitochondria. British Journal of Nutrition 69, 97-102.

Toyomizu, M., Kirihara, D., Tanaka, M., Hayashi, K.\& Tomita, Y. (1992). Dietary protein level alters oxidative phosphorylation in heart and liver mitochondria of chicks. British Journal of Nutrition 68, 89-99.

Trayhurn, P., Ashwell, M., Jennings, G., Richard, D. \& Stirling, D. M. (1987). Effect of warm or cold exposure on GDP binding and uncoupling protein in rat brown fat. American Journal of Physiology 252, E237-E243,

Truswell, A. S. (1975). Carbohydrate and lipid metabolism in protein-calorie malnutrition. In Protein-Calorie Malnutrition, pp. 119-141 [R. E. Olson, editor]. New York: Academic Press.

Webster, A. J. F. (1981). The energetic efficiency of metabolism. Proceedings of Nutritional Society 40, $121-128$. 